avoidance of jargon, the doctor's attitude, careful supervision, gadgets such as pill boxes as an aid to memory, enabling patients to express their anxieties and avoidance of conflicting information. The attitude of the doctor appears to be paramount. 'The sympathetic doctor's instructions and explanations are followed, understood and remembered better than those of a doctor who appears cold and uninterested'.

In all, this is a thought-provoking and challenging booklet which will be a great help to all who have to teach medical students and are conscious of their own shortcomings in their dealings with patients. One small quibble is with the use of the word 'compliance' which seems now to have become established in the literature of doctor-patient communication. It is surely more applicable to what a sergeant major tries to achieve with raw recruits. When we are trying to help patients perhaps 'co-operation' would be more appropriate

The illustrations drawn by John Moll are both apt and funny.

P A ANDERSEN

\section{Medical Responsibility: Paternalism, Informed Consent and Euthanasia}

Wade L Robison and Michael S Prichard (Eds).

Humana Press, 1979, 240 pp. \$19.50.

Most of the thirteen papers in this collection were originally presented at a conference on Philosophy, Law and Medicine held in Michigan in 1976. Several have already been published elsewhere. The main topics are: the definition and justification of paternalism, the ethics of experiments on human subjects, non-therapeutic fetal experimentation, and euthanasia. In spite of the book's origins the editors do not regard it simply as another volume of conference proceedings. They intend it as an introduction to medical ethics which will display the common moral concerns underlying apparently diverse problems. Some of the papers, notably Childress's 'Paternalism and Health Care' and Rachels' 'Euthanasia, Killing and Letting Die', would indeed constitute excellent introductions to their topics. Others, for example Gert and Culver's 'The Justification of Paternalism', serm to demand too much philosophical sophistication for this purpose.

With one exception (Beauchamp's reply to Rachels), the papers are entirely independent of one another, so there is little sense of debate among the contributors. Equally the editors make no serious attempt to show how discussion of the different topics might be linked together. This is a pity, since it would be easy to draw instructive and fruitful parallels. For example, the papers on paternalism and experimentation on human subjects naturally concentrate on questions about selfdetermination. Is informed consent always required? What does it mean? What are the practical difficulties in ensuring that subjects really do consent? All these questions need also to be raised about proposals to legitimise voluntary euthanasia.

But the papers on euthanasia included in this volume say nothing about these questions. Instead they discuss the difference, if any, between killing and letting die and the definition of death. In themselves these papers are excellent but their inclusion in the present volume does not help the reader to see the common moral concerns underlying diverse problems.

Most of the contributors appear to be professional philosophers and this gives the volume as a whole a certain one-sideness. Although all the authors have conscientiously illustrated their points with medical examples one sometimes feels that the argument may be getting a little remote from the realities of medical practice.

Thus taken as a whole the volume does not fulfil its editors' ambitions. On the other hand most of the individual contributions do have something worthwhile to say. It is a volume which anyone working in medical ethics will need to consult.

R F STALLEY

Ethical issues in death and dying

Tom L Beauchamp and Seymour Perlin (Eds).

Prentice-Hall Inc, 1978, 368 pages, $£ 6.85$.

This book is divided into five sections called respectively: The Definition and Determination of Death; Suicide; Rights of the Dying Patient; Euthanasia and Natural Death; and The Significance of Life and Death. A short Introduction by the Editors sets the scene for each section and is followed by a number of articles or 'readings', some presumably written for this volume and others taken from the literature, past and present. They are arranged in the form of a debate with brief linking summaries and opposing viewpoints are juxtaposed. This reviewer found the format helpful as through this type of analysis and argument the danger of over-simplification of what are very complex ethical issues is stressed. A good example is the Harvard Definition of Brain Death (or irreversible coma) which at the time of its introduction in 1968 was considered to be unambiguous and straightforward, yet as Veatch and Jonas, among others, indicate, there are problems with this definition and it has required modification in subsequent years. Many are still unhappy with it and its implications.

I liked the section on the 'Rights of the Dying Patient' and I hope that many present and future clinicians will study it. Widely divergent views are expressed on the conflict that may occur between what a doctor views as his professional obligation to treat a patient and the patient's right to refuse treatment. Legally, 'there is the fear that any exception to the sanctity of life cannot but cheapen it' (Hegland), yet 'Human dignity is enhanced by permitting the individual to determine for himself what beliefs are worth dying for'. (Cantor). The section on 'Euthanasia', that most contentious of contemporary issues, includes the familiar arguments about 'active' and 'passive' euthanasia. (Almost inevitably there is a review of some of the issues in the Quinlan case.)

Discussion on the particularly poignant problem of defective newborn infants concentrates on the legal issues involved. Robertson and Fost point out the dangers of physicians claiming the right to act in defiance or ignorance of existing laws. They suggest that we need 'either a set of authoritative criteria describing the limited circumstances in which ordinary care may be withheld from defective newborn infants or a process of decision-making which minimises the risk of abuses or mistakes'. Such processes have been developed but are not enough in themselves without some equivalent change in the law. Fear of the 
law too often deters a physician from acting in his patient's best interests and from helping families face problems realistically. At present we have Catch-22. A change in the law is needed to demonstrate that a change in the law is wise and safe from abuse.

Finaily, there is a philosophical debate on the significance of life and death in which the views of such writers as Tolstoy and Camus are analysed by modern philosophers. The view that life is absurd and meaningless ('endless pointlessness') is considered to be too pessimistic. Life has meaning only in the way we set our own objectives and make our own choices. Thus, as Margolis argues, to consider death itself as intrinsically evil is arbitrary and doctrinaire - it depends on the circumstances!

In the Preface the editors indicate their confidence that this book will serve as a text for interdisciplinary discussions on the issues of death and dying in our technologically advanced society. Overall, I think that this confidence is justified. In whole or in parts it should be helpful to students and practitioners of medicine and law. (It is of course primarily concerned with American law). There are one or two editorial slips such as incomplete references, but overall the book is well written, well produced and available in paperback at reasonable cost. Many of the contributors are familiar to this reviewer, but some are not. Unfortunately, we are not told who they are - not even their professional or academic affiliations. Brief biographical notes would have helped.

A G M CAMPBELL

\section{Contemporary Issues in Biomedical Ethics}

John W Davis, Barry Hoffmaster and Sarah Shorten (Eds).

Humana Press, I978, 300 pp. \$I 9.50.

This book is a collection of papers and comments thereon originally delivered at a Colloquium on Biomedical Ethics at the University of Western Ontario in 1977, with a foreword by Daniel Callahan of the Hastings Center.

Because the term 'biomedical' is susceptible of a wide definition the essays are a selection which have this in common, that they are observations on recent advances in biology and the health sciences which have created a need to re-assess the practice of medicine and the attitudes and values of society. There are five parts: rights and moral decisions, issues in genetics, the role of the physician, informed consent and paternalism, and professional responsibility.

In the first four parts, each main contribution is followed immediately by comment and criticism, but for some reason, which is not immediately apparent, this useful and stimulating technique has not been adopted in the fifth part where the essays are no less provocative, but the authors' views nevertheless appears unchallenged.

The book opens with an essay by John Ladd entitled 'Legalism and Medical Ethics', where legalism is defined as 'the ethical attitude that holds moral conduct to be a matter of rule following, and moral relationships to consist of duties and rights determined by rules'. In his view, legalism is an inappropriate device for discussing medical ethics. Because of its association with rights, it entails 'the legalisation of morality and the moralisation of law'. Ladd would prefer a more individualistic approach based on moral relationships and duties. His stance fails to meet with the approval of Hoffmaster whose principal objection is that Ladd's approach does not amount to a theory of ethical conduct, in other words it fails to identify the characteristics of right action and to provide a method for choosing between alternatives.

Robert Audi's essay on 'The Moral Rights of the Terminally Ill' supports the notion of rights and he is of the view that conflicts of rights create the main problems in medical ethics. He attempts to clarify the idea of 'rights' and how to deal with conflicts and he begins by arguing that there is a moral distinction between killing and letting a person die. $\mathrm{He}$ goes on to discuss when terminally-ill patients should be allowed to refuse treatment or further treatment and thus recognises a right to control one's body, to end one's life and a right not to be lied to about one's condition. However, these rights can be overridden by more important moral considerations. Susan Sherwin does not hold with the distinction between killing and letting die nor with the view that rights in one person correlate with obligations in another.

The notion of patients' rights central to Joseph Ellin's essay, 'Sterilisation, Privacy and the Varase of Reproduction,' which is in the second section of the book. He acs whether it is rational and product of substantial benefit to permit 711 to reproduce, rather than requir@g some not to do so, while allowisg them to adopt instead. He concludes that it is not, but nevertheless hots that involuntary sterilisation is a violation of the right to use orfs s body. He also points to eth statements about the 'rights' of 更e unborn which he finds unintelligible. In that connection, Robert Bakct's essay, Protecting the Unconceivad! and Michael Bayles' observations thereon are instructive. Both asoce on the vagueness of the term 'genetic', a point which is develo d in Richard Hull's contribution, (6)

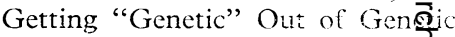
Disease'.

In the third section, Lisa New $\overrightarrow{\mathrm{e}}_{\mathrm{n}}$ suggest that modern medicine tras rendered the Hippocratic principtes otiose in that the practice of medigne is no longer for the select few, But Donald Zafras feels that m禺 remains of Hippocratic docte which is worth preserving and On be adapted to modern trents. Bayles puts forward the view that the physician is a 'body mechanie', in other words, the doctor pat relationship is fiduciary rather thin contractual and he argues that physician must be licensed $\Phi_{t o}$ 'practise' and must obtain prmission before performing mingr 'repairs'. Colleen Clements rej@ts this notion inter alia because Bayzes' premise depersonalises the role응 the doctor.

In one of the essays in the fou $\frac{D}{\text { Tht }}$ th part, Bernard Dickens details thie legal requirements for infornos consent, its elements, the requingd standards and he mentions som the problems which can arise with the mentally ill and those under This is complemented by Glem Graber and Ellin's discussion of 'Paternalism and Health Care' also Dan Brook and Bruce Miller- - n the 'Involuntary Commitment $\overline{\text { of }}$ the Mentally Ill'

The last part of the book contans three essays, one by Arthur Dock who emphasises the importance of compassion and suggests that students can be taught how tog compassionate. Josephine Flah 